\title{
Comparison between Measured Data-Carrying VDSL2 Cable Radiation and Radiation Limits for Wire-Line Telecommunication Networks
}

\author{
Josip MILANOVIC, Ana KATALINIC MUCALO, Mario GAL \\ Croatian Regulatory Authority for Network Industries, R. F. Mihanovica 9, 10110 Zagreb, Croatia \\ josip.milanovic@hakom.hr
}

Submitted July 29, 2020 / Accepted December 9, 2020

\begin{abstract}
Digital subscriber line (DSL) is a technology that is widely used for bringing high-speed Internet access to the users' premises. Unfortunately, the use of the DSL over existing copper telecommunication networks can result in radiation that can cause interference to radio systems operating in the same frequency range. To restrict such radio disturbances various radiation limits for wire-line telecommunication networks have been proposed. However, radiation limits differ significantly from each other which makes it difficult to adopt common protection criteria. In this paper, the comparison between defined radiation limits and measurements of the E-field radiation from the copper telecommunication cable is performed based on the measurement methodology described in the ITU-T K.60 Recommendation. The aim of the measurement was to assess whether the radiation from the aerial copper telecommunication cable (type: TK59U-xDSL) when VDSL2 profile 17 a technology is used, meets radiation limits mostly used in the European Union. Measurement results have shown that the radiation from the cable is approximately $6 \mathrm{~dB}$ above limits proposed by the ECC/REC(05)04 Recommendation, which could cause intolerable errors in radio signal reception, thus disabling radio service to operate as intended. The obtained results show that the power spectral density (PSD) should be reduced by $10 \mathrm{~dB}$ in order to assure an adequate protection of radio services.
\end{abstract}

\section{Keywords}

Electromagnetic interference, radio emission, radiation limits, TK59U-xDSL cable, VDSL2

\section{Introduction}

A rapid development of communication systems and their successful application in the communication market have deeply affected people's habits and living standard. With the need for an immediate access to information, end users demand higher throughput, greater data transfer reliability, larger number of available services, etc. Several high-speed technologies are used to accomplish these user requirements such as: digital subscriber line (DSL) technologies, fiber optics technologies, satellite technologies and wireless broadband technologies ( $3 \mathrm{G}, 4 \mathrm{G}$ and $5 \mathrm{G})$, etc. Each of the aforementioned technologies has advantages and disadvantages, and their application depends on purpose, implementation cost and availability. Technologies that are frequently used for broadband services are DSL technologies. They are especially interesting for telecommunication operators since they use the existing copper telecommunication network which significantly reduces installation time and implementation cost [1-3].

DSL come in a number of variants. Selection of appropriate DSL technology depends on the required throughput, the distance between the customer premises (CPE) and the central office (CO), symmetry of upstream and downstream traffic, service price, etc. Depending on the chosen technology, throughput can vary from several hundred kbps to several hundred Mbps. Higher throughput over copper telecommunication network requires greater frequency bandwidth, which can be achieved on higher frequencies of transmission [4-6].

Unfortunately, increasing throughput by increasing frequency bandwidth has its disadvantages. It is known that the copper wire is not a perfect transmission medium and that part of the signal energy is radiated in the air when the signal passes through the wire [7-9]. This radiation can cause unwanted interference with radio services using the same frequency spectrum, such as: amateur services, aeronautical services, broadcasting services, government services and various public safety services [10].

If radiation from the telecommunication network is too high, the radiated electromagnetic field can cause intolerable error in signal reception, and consequently it could cause loss of radio communication. Therefore, it is important to limit radiation from wire-line telecommunication networks, especially in order to protect critical services where such radiation can directly affect the safety and security of human life. To restrict such interference to radio services various limit values and mitigation techniques have been proposed, either by international institutions 
(such as International Telecommunication Union - ITU, Federal Communications Commission - FCC, Conference of European Post and Telecommunication administrations - CEPT, etc.) or by national telecommunication authorities. While the former have status of Recommendation, the latter have legal status in a particular country. In either case it is important to determine adequate limits which will ensure the protection of radio services operating in the same frequency range as DSL technologies.

Although copper telecommunication networks, due to their accessibility, are widely used for modern broadband high-speed technologies, the influence of the network radiation on the radio services operation and compliance between network radiation with defined radiation limits level are not investigated as much as could be expected. In [11] the theoretical background to the field problem and approximation formulae for the prediction of radiation from twisted-wire pairs are given. In order to prevent the impact of cable radiation on radio services, in [12-15] the authors suggest that the operator shall be required to cease part of the network causing interference or to replace critical part of the network with optical or higher quality copper cables (S/FTP cables). Although proposed solution has long-term viability, difficulties in the installation process, legal constrains, and the cost of new cable deployment, limits the application of this approach. In [10] windowing technique is proposed for lowering the level of cable radiation. Unfortunately, applying a windowing technique introduces signal distortions that are generally not easy to compensate. Other methods used to reduce radiation from the telecommunication infrastructure include adaptive notch filtering and using alternative filter banks [16-21]. However, using filters leads to data rate reduction and increases the complexity of the system.

To avoid possible contamination of the frequency spectrum and enable the coexistence of DSL technologies with other radio services operating in the same frequency band, ITU proposes to use interference mitigation techniques (e.g. notch filters) as a solution in case radiation levels are not met. However, it is noteworthy to evaluate how appropriate and efficient the proposed radiation limits are in the first place.

To that goal, we have made series of measurements of the electric field (E-field) radiation from VDSL2 data-carrying cable and compared them with the proposed radiation limits in order to investigate whether the measured cable radiation meets the proposed limits or not.

It should be noted that measurement methodology is described in the ITU-T K.60 Recommendation and that proposed limits can be applied only if measurements are carried out according to the defined measurement setup. However, in this paper we have expanded the measurement methodology to cases that are not covered by the Recommendation, but which can be encountered in practice.

The key points provided by this paper are:
- The proposed radiation limits are evaluated based on measurements. Two measurement setups were used. The first one was carried out with the antenna at the distance of $3 \mathrm{~m}$ from the cable, which is in line with the values defined in the recommendations. The second measurement was conducted at distances of $1 \mathrm{~m}$ and $3 \mathrm{~m}$, which is in fact a novel scenario that is not specifically addressed in recommendations, but occurs often in practice and should be investigated.

- Based on the comparison between measurement results and proposed radiation limits level, reduction of the power spectral density (PSD) mask is proposed in order to meet radiation limits condition.

- Although radiation limits are not defined for the unbalanced cable, in order to get the insight of how much the radiated E-field level can differ from balanced cable, additional measurement was performed when one wire from the twisted-wire pairs was disconnected (unbalanced cable).

The paper is organized as follows. Section 2 provides information of the VDSL2 technology. In Sec. 3 methods for radiation reduction from a wire-line telecommunication cable as well as technical specifications regarding the tested cables are given. In Sec. 4 the radiated emission from wire-line telecommunication networks is presented. Section 5 provides information about the measurement scenario and procedure, while measurement results, with the evaluation of the E-field radiation, are presented in Sec. 6. Conclusion remarks are given in Sec. 7.

\section{Overview of the VDSL2 Technology}

In line with the strategy of the European gigabit society, by the year 2025, all European households, rural and urban, should have an access to a network offering a download data rate of at least $100 \mathrm{Mbps}$. Fixed broadband system that will be involved to achieve that goal is VDSL2 technology [22], [23]. VDSL2 technology consists of different profiles. Each profile is a predefined set of implementation capabilities, which are characterized by the maximum aggregate downstream transmit power, number of carriers and frequency bandwidth. The profile selection also defines the maximum achievable data rates. For example, profile $30 \mathrm{a}$ uses frequency range up to $30 \mathrm{MHz}$ and provides data rate up to $200 \mathrm{Mbps}$, while profile $17 \mathrm{a}$ uses frequency range up to $17.664 \mathrm{MHz}$ and provides data rate up to $100 \mathrm{Mbps}$ over copper telecommunication network [24]. Generally, the larger frequency bandwidth is used, the higher data rate will be achieved [25]. However, using larger frequency bandwidth also has negative effects to the system, such as: decrease of the local loop length (the loop from the $\mathrm{CO}$ to the CPE) and the increase of the number of the radio services that could be affected by the data-carrying xDSL cable radiation. 


\section{Radiation from (xDSL) Telecommunication Network}

When transmitting VDSL2 signal over the copper telecommunication network, the electromagnetic field is radiated from the cable [11]. This radiation can be the source of interference to the radio systems operating at the same frequencies as VDSL2 if radio system antenna is set in the vicinity of VDSL2 data-carrying cable [26]. Intensity of disturbances caused by radiated electromagnetic field depends on used telecommunication networks. Generally, telecommunication network can be underground and aerial. While radiation from underground cable can be neglected, the radiation from wire-line telecommunication networks using aerial cables can interfere with radio services operating in the same frequency range. This is due to the fact that aerial cables, unlike the underground ones, can be placed close to the radio system receiving antenna.

In order to decrease radiation from aerial cables, twisted cables are used instead of flat ones. Radiation reduction in twisted cables comes from the fact that field generated by a twisted pair of wires has different sign but equal magnitude which results in mutual field cancellation [11], as shown in Fig. 1. Effective cancellation of the electromagnetic field radiation depends on the twisting length of pairs of wires in the cable that must be less then $\lambda_{\min } / 4$, where $\lambda_{\min }$ represents the minimal wave length of the signal in the cable. If twisted cable is not designed properly, transmitted signal in the cable may result in higher cable radiation [27], [28]. In a flat cable, the radiation from the pair of wires has equal sign and equal magnitude resulting in the increase of a total radiated field [11].

To describe the capability of the cable to reject the external noise and/or to decrease unwanted radiation, the term balanced is used. The balance of the cable, in the term of voltage, is defined as [11]

$$
b_{v}=\frac{U_{\text {com }}}{U_{\text {diff }}}
$$

where $U_{\text {com }}$ represents common mode voltage and $U_{\text {diff }}$ represents differential mode voltage. In the decibel scale, the cable balance is often described as a longitudinal conversion loss $(L C L)$, defined as [29]

$$
L C L=-20 \log _{10}\left(b_{\mathrm{v}}\right) \quad[\mathrm{dB}] .
$$

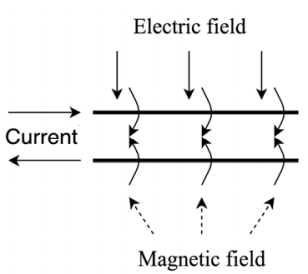

(a)

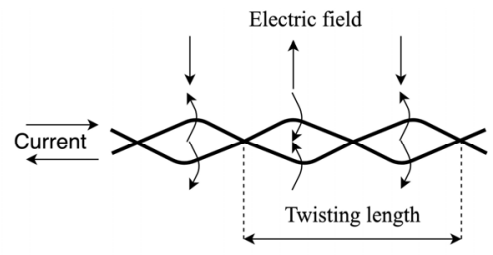

(b)
Fig. 1. An electromagnetic field radiation by: (a) flat cables, (b) twisted cables.

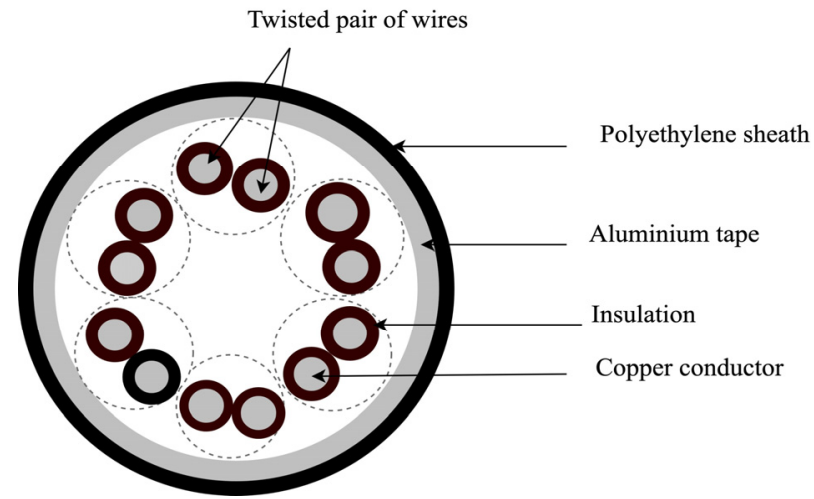

Fig. 2. Structure of the TK59U-xDSL cable.

One of the main factors that makes application of broadband services difficult is the use of old copper cables which are not primarily designed for the efficient data transmission on higher frequencies. Such cables are not shielded or balanced, and they are mainly used for the voice transmission. Modern xDSL aerial telecommunication cables consist of several pairs of wires which are twisted over each other [30]. To prevent damages caused by the penetration of moisture in the cable all interstices in the cable are filled with special filling compound. Additionally, cables are shielded with aluminum tape in order to reduce radiation from the cable as well as to reduce external radio impact. Aluminum tape is then covered with polyethylene sheath that additionally protects the cable from external influences (mechanical and weather influences). The internal layout of the telecommunication cable TK59U-xDSL used in this paper is shown in Fig. 2.

\section{Radiation Limits from Wire-line Telecommunication Networks}

To prevent unwanted emission and assure adequate interference protection of radio users, radio spectrum must be managed and monitored by national and/or international administrations.

ITU as a United Nation specialized agency for information and communication technologies published ITU-T K.60 Recommendation which provides protection limits against interference from wire-line telecommunication networks. Radiation limits defined by the ITU for frequency range from $9 \mathrm{kHz}$ to $30 \mathrm{MHz}$ are shown in Tab. 1 [31]. Another document that is frequently used as a reference document for the assessment of radio interference caused by radiation from wire-line telecommunication networks is ECC/REC/(05)04 Recommendation developed by CEPT. Radiation limits defined by the ECC for frequency range from $9 \mathrm{kHz}$ to $30 \mathrm{MHz}$ are shown in Tab. 2 [32].

In Norway, radiation from wire-line telecommunication networks in the frequency range up to $30 \mathrm{MHz}$ are regulated according to levels provided in Tab. 3. Although this regulation was initially proposed by the Norwegian 


\begin{tabular}{|c|c|c|c|}
\hline $\begin{array}{c}\text { Freq. range } \\
\text { [MHz] }\end{array}$ & $\begin{array}{c}\text { Field strength limit } \\
\text { (peak detector) } \\
\text { [dB } \boldsymbol{\mu} \mathbf{V} / \mathbf{m}]\end{array}$ & $\begin{array}{c}\text { Meas. } \\
\text { distance } \\
\text { [m] }\end{array}$ & $\begin{array}{c}\text { Meas. } \\
\text { bandwidth } \\
\text { [kHz] }\end{array}$ \\
\hline 0.009 to 0.15 & $52-20 \log _{10}(f)$ & 3 & 0.2 \\
\hline 0.15 to 1 & $52-20 \log _{10}(f)$ & 3 & 9 \\
\hline 1 to 30 & $52-8.8 \log _{10}(f)$ & 3 & 9 \\
\hline
\end{tabular}

Tab. 1. Radiation limits proposed in the ITU-T K.60 Recommendation.

\begin{tabular}{|c|c|c|c|}
\hline $\begin{array}{c}\text { Freq. range } \\
\text { [MHz] }\end{array}$ & $\begin{array}{c}\text { Field strength limit } \\
\text { (peak detector) } \\
\text { [dB } \boldsymbol{\mu} \mathbf{V} / \mathbf{m} \text { ] }\end{array}$ & $\begin{array}{c}\text { Meas. } \\
\text { distance } \\
\text { [m] }\end{array}$ & $\begin{array}{c}\text { Meas. } \\
\text { bandwidth } \\
\text { [kHz] }\end{array}$ \\
\hline 0.009 to 0.15 & $40-20 \log _{10}(f)$ & 3 & 0.2 \\
\hline 0.15 to 1 & $40-20 \log _{10}(f)$ & 3 & 9 \\
\hline 1 to 30 & $40-8.8 \log _{10}(f)$ & 3 & 9 \\
\hline
\end{tabular}

Tab. 2. Radiation limits proposed in the $\mathrm{ECC} / \mathrm{REC} /(05) 04$ Recommendation.

\begin{tabular}{|c|c|c|c|}
\hline $\begin{array}{c}\text { Freq. range } \\
\text { [MHz] }\end{array}$ & $\begin{array}{c}\text { Field strength limit } \\
\text { (peak detector) } \\
\text { [dB } \boldsymbol{\mu} \mathbf{V} / \mathbf{m}]\end{array}$ & $\begin{array}{c}\text { Meas. } \\
\text { distance } \\
\text { [m] }\end{array}$ & $\begin{array}{c}\text { Meas. } \\
\text { bandwidth } \\
\text { [kHz] }\end{array}$ \\
\hline 0.15 to 1 & $20-20 \log _{10}(f)$ & 3 & 9 \\
\hline 1 to 30 & $20-7.7 \log _{10}(f)$ & 3 & 9 \\
\hline
\end{tabular}

Tab. 3. Radiation limits proposed in by the Norwegian administration.

administration, it is also fully accepted by several other CEPT administrations (e.g. Ireland), while some other countries only partially accepted proposed limits (e.g. United Kingdom) [33], [34].

As can be seen from the tables, limits proposed by the aforementioned recommendations, national or international, can vary up to a few dozen decibels, which complicates the comparison and the analysis of measurement results. From the customer's point of view, it can also cause confusion regarding the validation of the procedure that defines radiation protection criteria. Since radio spectrum management at European level is administered by the CEPT/ECC, and in order to avoid confusion of results interpretation, this paper is focused on limits defined in the ECC/REC(05)04 document.

\section{Measurement Scenario and Procedure}

The radiation level of VDSL2 profile 17a broadband technology is measured in the city of Rijeka, Croatia. PSD mask as well as frequency spectrum allocation for VDSL2 profile 17a (998ADE17-M2x-B band plan) can be found in [35]. Signal radiation was observed when the aerial TK59U-xDSL telecommunication cable is used. This cable consists of six twisted pairs of wires, each with $0.5 \mathrm{~mm}$ diameter. To decrease the radiation from the cable as well as to protect data transmission against the external radio impact, the cable is shielded with $0.2 \mathrm{~mm}$ aluminum tape.

For measurement purposes the following equipment was used: the Rhode\&Schwarz ESMD wideband monitor- ing receiver (type: 4066.0004K03) and the Rhode\&Schwarz loop antenna type BN150012 (0.8 m diameter). Antenna was mounted on a tripod in a way that center of the loop antenna is $1 \mathrm{~m}$ above ground level at the location previously identified as the one with the highest maximum Efield radiation. To analyze radiation from the aerial VDSL2 data-carrying cable, two types of measurements are provided. In the first type of measurement, the radiated E-field level was measured when the antenna was mounted $3 \mathrm{~m}$ below the aerial cable (Fig. 3a) as defined in [31]. Additionally, the E-field radiation when one of the wires from the twisted pair is disconnected is observed. In practice, this situation can be considered as the worst case, since the cable behaves like an "antenna" due to the cable unbalance. Since customer antenna can be less than $3 \mathrm{~m}$ away from the cable (e.g. antenna of the amateur radio service), in the second type of measurement, the attenuation of the cable radiation with distance when using vertical VDSL2 data-carrying cable was investigated. To do that, E-field radiation from the cable is firstly measured when the center of the antenna was mounted $1 \mathrm{~m}$ from the cable. After that the center of the antenna was mounted $3 \mathrm{~m}$ from the cable and measurement was repeated (Fig. 3b). Measurements are carried out in the customer vicinity (15 $\mathrm{m}$ away from the CPE location and $600 \mathrm{~m}$ away from the CO location). To minimize the possibility of earth loops affecting the measurement results, the receiver and the loop antenna had battery power supply (independent power source with no ground connection), as recommended by [34].

The Rhode\&Schwarz ESMD receiver is set up to measure frequency range from $100 \mathrm{kHz}$ to $20 \mathrm{MHz}$ with $5 \mathrm{kHz}$ frequency step. All measurements are provided with a peak detector and $9 \mathrm{kHz}$ measuring bandwidth, according to [32]. In order to get E-field level in $\mathrm{dB} \mu \mathrm{V} / \mathrm{m}$, antenna correction factor as well as cable loss and connector loss were added to the values measured at the receiver. Antenna correction factor is provided by the antenna manufacture.

In order to find the maximum received signal, after the antenna is placed in the proper location and the receiver is set up to the required parameters, the antenna is rotated around vertical axis. Once the required antenna position has been found, the measurement procedure started.

\section{Measurement Results Evaluation}

In order to decrease the influence of the men-made noise to the measurement results, measurements are carried out in the rural area of the city of Rijeka, Croatia. For the upstream (US1 and US2), as well as for the downstream (DS2 and DS3) frequency bands the mean value, $\bar{x}$, and standard deviation, $\sigma$, of the measured results were calculated. The upstream and downstream frequency plan for VDSL2 profile 17a (998ADE17-M2x-B band plan) is defined in [35]. The aggregate power of the modem is set up to $P_{\mathrm{DS}}=11.9 \mathrm{dBm}$ at the $\mathrm{CO}$ location and $P_{\mathrm{US}}=9.4 \mathrm{dBm}$ at the CPE location. In order to obtain the reference (noise) Efield level in the frequency range from $100 \mathrm{kHz}$ to $20 \mathrm{MHz}$ 


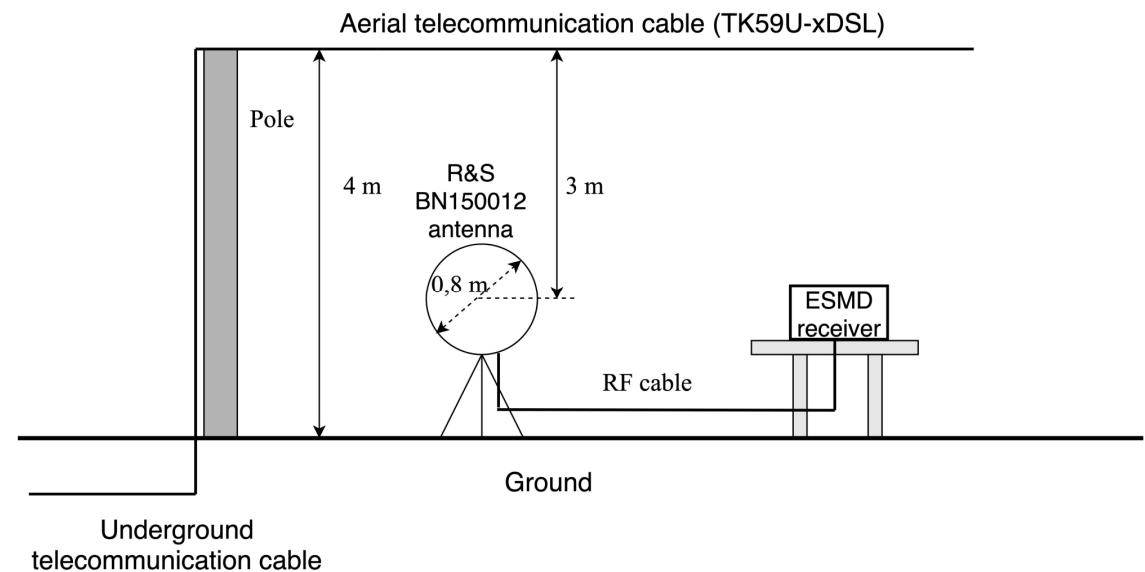

(a)

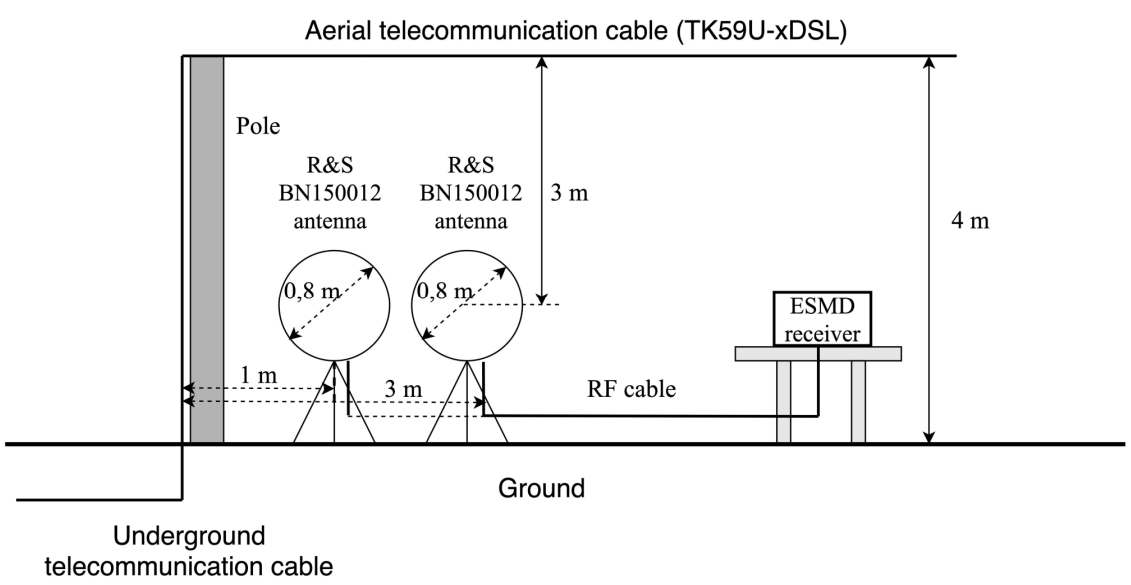

(b)

Fig. 3. Measuring antenna position: (a) the first measurement type (cable is in the horizontal position) and (b) the second measurement type (cable is in the vertical position)

the measurement was firstly made when VDSL2 signal was not transmitted via the cable (no radiation from the cable). The measurement is carried out when the antenna is set up $3 \mathrm{~m}$ below the aerial TK59U-xDSL cable (first type of the measurement, Fig. 3a). The result of this measurement is presented in Fig. 4 and Tab. 4. Narrowband signals with magnitude higher than $10 \mathrm{~dB}$ above noise level are signals transmitted by the radio services operating in the frequency range up to $20 \mathrm{MHz}$. High magnitude of the E-field value in the first part of the spectrum (up to approximately 3.0 MHz), presented in Fig. 4, is the result of the lower antenna sensitivity. Therefore, only US1 and US2, as well as DS2 and DS3 frequency bands were considered in this paper. After the reference E-field level is determined measurement was repeated when VDSL2 signal is transmitted through the TK59U-xDSL cable. Result of this measurement is shown in Fig. 5. Figure 5 shows that Efield radiation from the cable in the US frequency band, when the balanced cable is used, has a higher value then at the adjacent DS frequency band. For example in the US1 frequency band the mean value $\bar{x}$ and standard deviation $\sigma$ of the received $E$-field radiation are $\bar{x}_{\mathrm{US} 1 \_ \text {bal }}=33.7 \mathrm{~dB} \mu \mathrm{V} / \mathrm{m}$ and $\sigma_{\mathrm{US} 1 \text { bal }}=1.9 \mathrm{~dB}$ while in the adjacent DS2 frequency band those values were $\bar{x}_{\mathrm{DS} 2 \text { bal }}=26.5 \mathrm{~dB} \mu \mathrm{V} / \mathrm{m}$ and $\sigma_{\mathrm{DS} 2 \text { bal }}=2.6 \mathrm{~dB}$. In the US2 frequency band the mean value is $\bar{x}_{\mathrm{US2} \_ \text {bal }}=30.8 \mathrm{~dB} \mu \mathrm{V} / \mathrm{m}$ and in the DS3 frequency band mean value is $\bar{x}_{\mathrm{DS} 3 \text { bal }}=26 \mathrm{~dB} \mu \mathrm{V} / \mathrm{m}$. Higher mean value in the upstream frequency bands is due to the fact that measurement was conducted close to the customer premises, resulting in smaller cable loss for the signal in upstream direction when compared with the downstream signal coming from a further CO location. The figure also shows the reduction of the radiation with the frequency increase which is the result of an increased cable loss and increased path loss between the cable and the antenna at higher frequencies.

The comparison between the measured E-field values and radiation limits defined in the $\mathrm{ECC} / \mathrm{REC} /(05) 04 \mathrm{Rec}-$ ommendation when the TK59U-xDSL telecommunication cable is used are presented in Fig. 6.

As it can be seen in Fig. 6, the radiated power in the US frequencies bands at discrete frequencies are above limits proposed by the ECC. In the US1 frequency band the highest radiation of the E-field is measured at $5.18 \mathrm{MHz}$ and it is $39.3 \mathrm{~dB} \mu \mathrm{V} / \mathrm{m}$ while in the US2 frequency band the highest E-field radiation is measured at $11.45 \mathrm{MHz}$ and it is $37.4 \mathrm{~dB} \mu \mathrm{V} / \mathrm{m}$. According to Tab. 2 at $5.18 \mathrm{MHz}$ the proposed radiation limit is $33.7 \mathrm{~dB} \mu \mathrm{V} / \mathrm{m}$ while at $11.45 \mathrm{MHz}$ radiation limit is $30.6 \mathrm{~dB} \mu \mathrm{V} / \mathrm{m}$. The radiation level at men- 


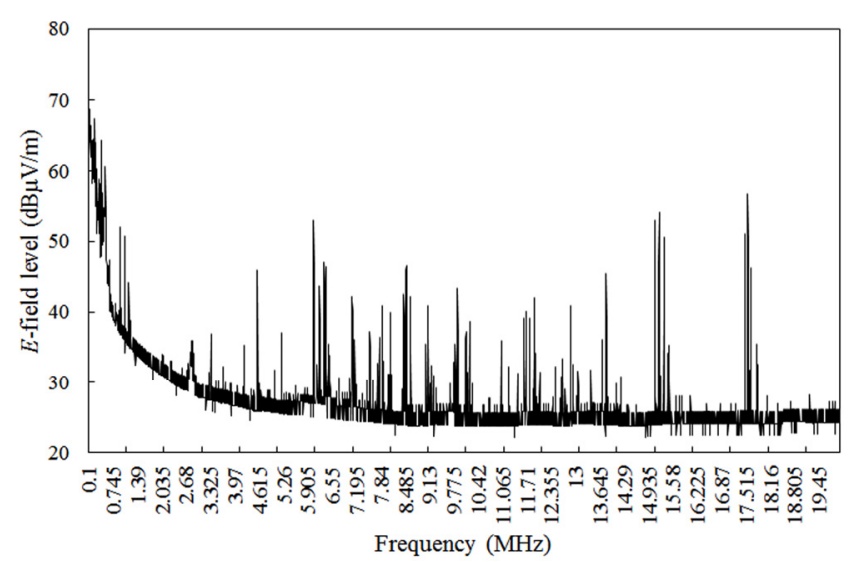

Fig. 4. The $E$-field reference level in the frequency range from $100 \mathrm{kHz}$ to $20 \mathrm{MHz}$.

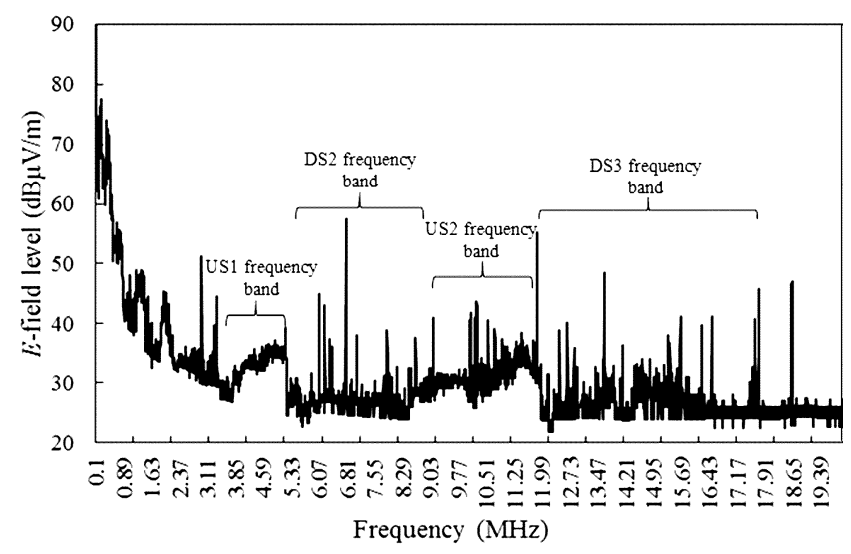

Fig. 5. The $E$-field level in the frequency range from $100 \mathrm{kHz}$ to $20 \mathrm{MHz}$.

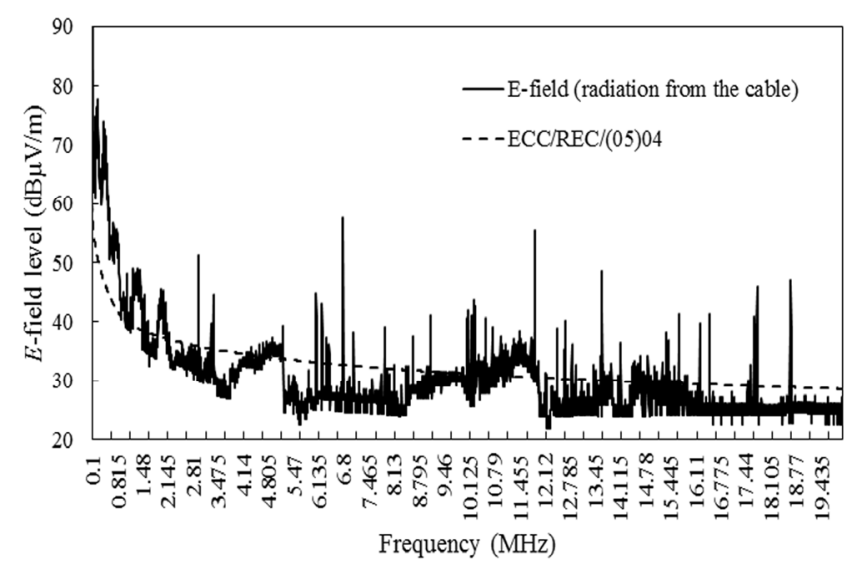

Fig. 6. Comparison of the E-field radiation and $\mathrm{ECC} / \mathrm{REC} /(05) 04$ radiation limits.

tioned frequencies is approximately $6 \mathrm{~dB}$ higher than limits proposed by the ECC/REC/(05)04 Recommendation. Since the sensitivity of a radio receiver is determined, among other things, with non-intentional radiators, according to the ECC/REC/(05)04 Recommendation, this increase of the emission above the proposed limits could cause a degradation of the radio signal reception. In order to keep radiation from telecommunication cable below the proposed radiation limits values, in this paper, according to the

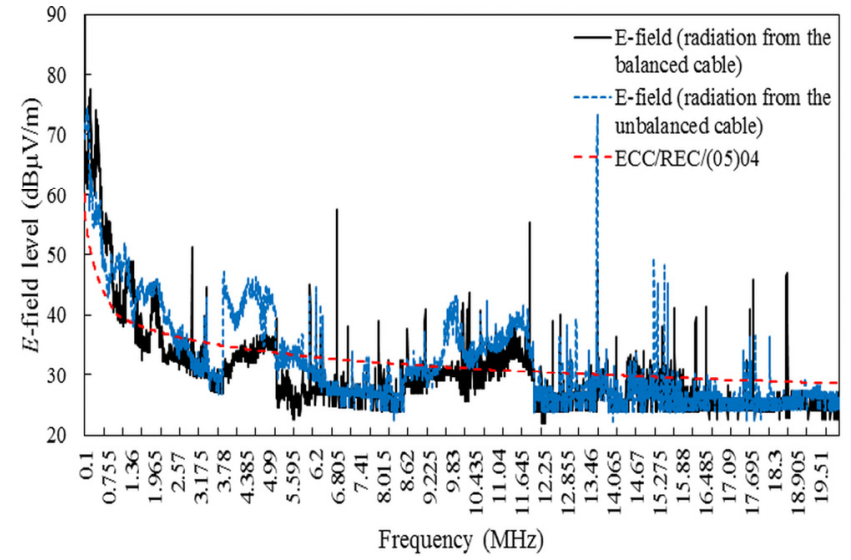

Fig. 7. Comparison of the measured E-field radiation from the balanced and the unbalanced cable with the $\mathrm{ECC} / \mathrm{REC} /(05) 04$ radiation limits.

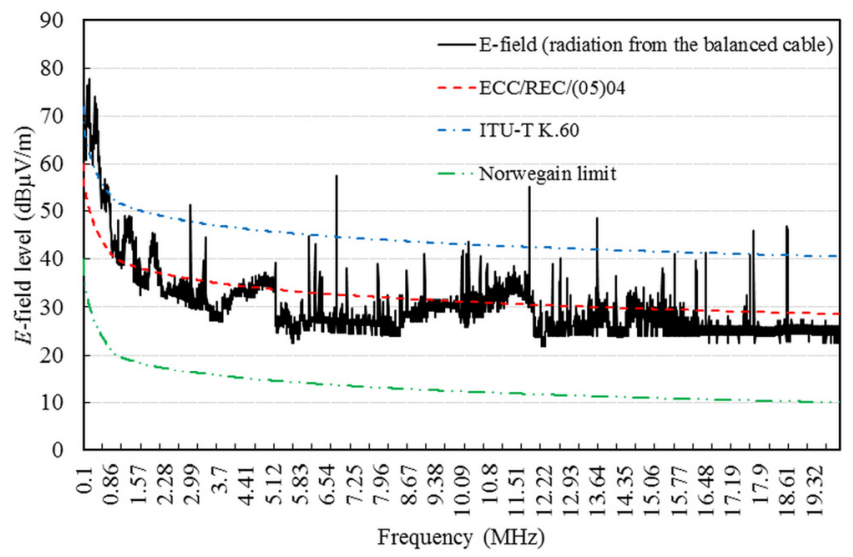

Fig. 8. Comparison of measured E-field radiation from the balanced cable with the proposed limits

presented measurement results, the reduction of PSD mask for $10 \mathrm{~dB}$ is proposed. Drawback of this approach is that it reduces the data rate transmission but this reduction is negligible compared to the data rate reduction when other methods are applied (e.g. using notch filters). The situation is even worse if one of the wires of the twisted pair of wires is disconnected (unbalanced cable). If unbalanced cable is used, due to the introduced differences in the amplitude and phase of the signals in the cable, the commonmode signal will cause an increase in radiation from the telecommunications cable [36]. Measurement results of the E-field radiation for both balanced and unbalanced cable are shown in Fig. 7.

From Fig. 7 it is seen that the E-field radiation of the unbalanced cable is higher than when the balanced cable is used. The mean value and standard deviation of the E-field radiation in the US1 frequency band when the unbalanced cable is used is $\bar{x}_{\mathrm{US1} \text { _un }}=42.3 \mathrm{~dB} \mu \mathrm{V} / \mathrm{m}$ and $\sigma_{\text {US1_un }}=3.3 \mathrm{~dB}$ while in the US2 frequency band the mean value and standard deviation are $\bar{x}_{\mathrm{US} 2 \mathrm{un}}=34.2 \mathrm{~dB} \mu \mathrm{V} / \mathrm{m}$ and $\sigma_{\mathrm{US} 2 \text { un }}=3.6 \mathrm{~dB}$. In the US1 frequency band the mean value of the radiation is $8.6 \mathrm{~dB}$ higher when the unbalanced cable is used than when the balanced cable is used, while in the US2 frequency band this difference is $3.4 \mathrm{~dB}$. The highest 
value of the E-field radiation in the US1 frequency band when the unbalanced cable is used is $48.3 \mathrm{~dB} \mu \mathrm{V} / \mathrm{m}$ measured at the $4.45 \mathrm{MHz}$ while in the US2 frequency band the highest value of the radiation is $43.4 \mathrm{~dB} \mu \mathrm{V} / \mathrm{m}$ at $9.91 \mathrm{MHz}$. That is $14.1 \mathrm{~dB}$ above the ECC radiation limits at $4.45 \mathrm{MHz}$ (US1 frequency band) and $12.1 \mathrm{~dB}$ above the proposed radiation limits at $9.91 \mathrm{MHz}$ (US2 frequency band), respectively. This significant increase of the radiation when the unbalanced cable is used can cause serious disturbances of the radio signal reception, thus disabling radio services to operate as intended. To avoid such scenario, cable parameters should be continuously monitored by the operator, and if necessary, cable repair or cable replacement should be done as soon as possible.

Comparison between the proposed radiation limits and measurement results when balanced cable is used is shown in Fig. 8 while mean value and standard deviation are given in Tab. 4.

Figure 8 shows that Norwegian limit is optimistic (mean value of limit values are below the mean value of the measured values) while ECC/REC/(05)04 and ITU-T $\mathrm{K} .60$ limits are pessimistic in the term of the radiation (mean value of the limit values are above the mean value of the measured values). Results of the comparison also showed that when the balanced cable is used in the US1 frequency band, the mean value of the measured values are $18.8 \mathrm{~dB}$ above Norwegian mean limits value, $0.5 \mathrm{~dB}$ below the $\mathrm{ECC} / \mathrm{REC} /(05) 04$ mean limits value and $12.5 \mathrm{~dB}$ below the ITU-T K.60 mean limits value.

In the US2 frequency band, the mean value of the measured values are $18.6 \mathrm{~dB}$ above the Norwegian mean limits value, $0.3 \mathrm{~dB}$ below the $\mathrm{ECC} / \mathrm{REC} /(05) 04$ mean limits value and $12.3 \mathrm{~dB}$ below the ITU-T K.60 mean lim- its value. Regarding Norwegian limits, results presented in Fig. 8 and Tab. 4 show that the proposed values are underestimated since all measured E-field values were above defined limits. Presented results also show that although the $\mathrm{ECC} / \mathrm{REC} /(05) 04$ mean limits value are above mean value of the measured values (Tab. 4), ECC limits do not offer adequate radiation protection. That is due to the fact that in the part of the US1 and US2 frequency band limit value proposed by the ECC/REC/(05)04 are below the measured values (Fig. 8) what could cause unwanted interference to radio service reception at discreet frequencies (e.g. $5.18 \mathrm{MHz}$ in the US1 frequency band and $11.45 \mathrm{MHz}$ in the US2 frequency band). Measurement results also showed that ITU proposed mean limit values are above the mean value of the measured values.

The radiation limits proposed by the ECC/REC(05)04 Recommendation are defined for the antenna position at $3 \mathrm{~m}$ from the cable. However, in practice, the antenna position is usually determined by the user premises constraints and it can be less than $3 \mathrm{~m}$ away from the datacarrying $x D S L$ cable. In order to investigate the attenuation of the E-field radiation with the distance from the vertical VDSL2 data-carrying cable (the second type of the measurement, Fig. 3b), radiation is firstly measured when the antenna is set up $1 \mathrm{~m}$ from the cable. After that the antenna is set up $3 \mathrm{~m}$ from the cable and measurement was repeated. Measurement results are presented in Fig. 9.

As it can be seen from Fig. 9, the mean received Efield radiation value at $1 \mathrm{~m}$ from the cable in the US1 frequency band is approximately $7 \mathrm{~dB}$ higher than at $3 \mathrm{~m}$ from the cable. In the US2 frequency band, the received Efield radiation from the cable is approximately $8 \mathrm{~dB}$ higher at $1 \mathrm{~m}$ from the cable compared to the measurement at the

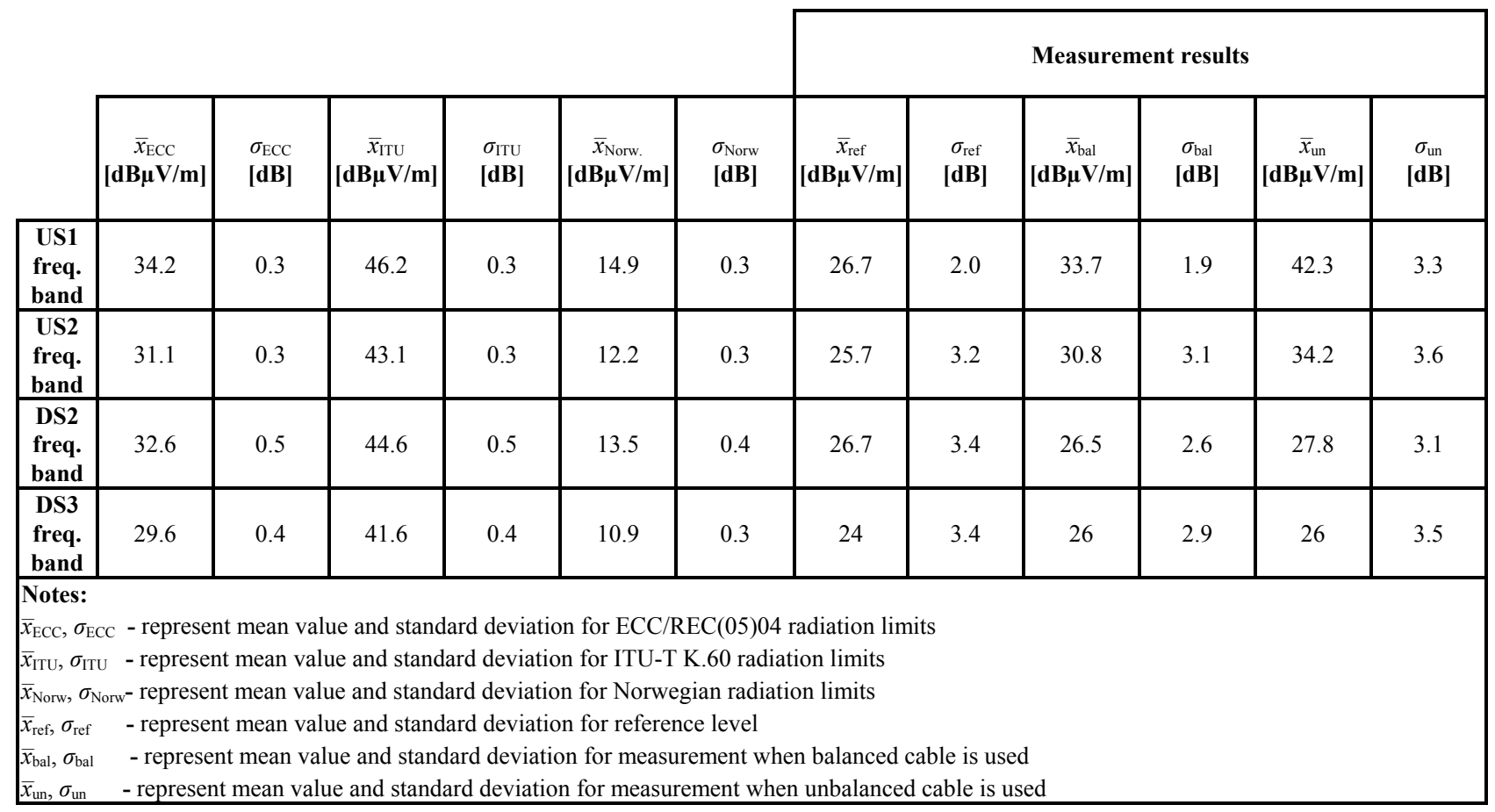

Tab. 4. Mean values and standard deviations of the proposed limits and the measured values. 


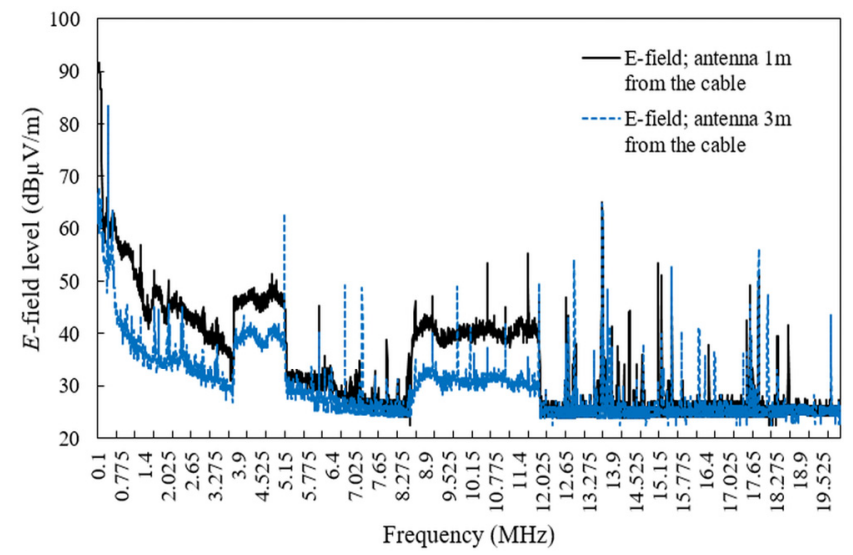

Fig. 9. Attenuation of the E-field radiation with distance for two antenna positions: at $1 \mathrm{~m}$ and $3 \mathrm{~m}$ from the cable.

$3 \mathrm{~m}$ from the cable. This result is expected since path loss increases with the distance between the antenna and the cable.

\section{Conclusions}

In this paper the radiation from the TK59U-xDSL cable when VDSL2 profile 17a technology is used has been measured and analyzed with the aim to evaluate whether the proposed radiation limits are met or not.

Presented results showed that the radiation from the cable at discreet frequencies in the US1 and the US2 frequency band is approximately $6 \mathrm{~dB}$ above limits proposed by the ECC/REC(05)04 Recommendation. Such increase of radiation above proposed limits value could cause intolerable errors in radio signal reception disabling radio service to operate as intended. Since radiation from the telecommunication cable generally depends on the cable structure, even higher disturbances to the radio signal reception could be expected in customer premises where unshielded cables for "in-house" telecommunication installation are widely used (e.g. UTP cat. 5 cable).

Radiation from cable when the unbalanced cable was used was also measured and analyzed. As expected, measurement results showed that radiation increases when the unbalanced cable is used in comparison when the balanced cable is used. The average value of the radiation is increased for $8.6 \mathrm{~dB}$ in US1 and $3.4 \mathrm{~dB}$ in US2 frequency band. Although Recommendations do not define limits for unbalanced cable, measurement results showed that the unbalanced cable can cause serious problem with radio signal reception and disable radio services operation as intended. Therefore, this situation has to be avoided whenever possible.

The comparison between radiation limits proposed in ECC/REC/(05)04, ITU-R K.60 and Norwegian legislation shows that ITU-T K.60 Recommendation proposed limits that are above measured values when TK-59U-xDSL cable is used, while other proposed limits, in all or in the part of the US1 and US2 frequency band, underestimate real-life radiation from the cable.

Measurement results and analysis given in this paper clearly indicate that total protection of radio service could be accomplished only if effective technique and methods for radiation reduction are applied. Based on the analysis of measurement results this paper proposes to reduce the PSD by $10 \mathrm{~dB}$, in order to assure that the radiation from TK59U-xDSL cable when VDSL2 signal is transmitted is below levels proposed by the ECC/REC(05)04 Recommendation. PSD reduction by $10 \mathrm{~dB}$ will reduce the data rate transmission but this reduction is negligible compared to the data rate reduction when other methods are applied (e.g. notching certain subchannels).

The proposed level of spectral mask reduction is based on the comparison between the measured E-field radiation values and $\mathrm{ECC} / \mathrm{REC}(05) 04$ radiation limits values when VDSL2 signal is transmitted through TK59UxDSL cable. Since, in practice, different types of telecommunication cables can be used for VDSL2 data transmission, different level of spectral mask reduction could be expected. In future research, the level of radiation when different types of cables (e.g. UTP, FTP and S/FTP cables) are used will be investigate and according to the measurement results, reduction of the spectral mask will be proposed for each cable types. Additionally, efficiency of other interference mitigation techniques (e.g. notching certain subchannels) will be analyzed as well as their impact on data rate reduction.

\section{Acknowledgments}

This work and the study behind it would not have been possible without the technical and financial support of the Croatian regulatory authority for network industries (HAKOM). We would also like to thank the following people without whom we would not have been able to complete this research, Goran Jurin M.Sc. for his enthusiasm, motivation and immense knowledge as well as our colleagues from the RF Spectrum Monitoring Department for assistance in data collection and insightful comments.

\section{References}

[1] LAFATA, P. Examination of multiplexing VDSL2 over ADSL2+ line. Elektronika ir Elektrotechnika, 2013, vol. 19, no. 8, p. 123-127. DOI: 10.5755/j01.eee.19.8.3116

[2] SVEDEK, V., JURIN, G., WEBER, M. Increasing availability of broadband access over copper network infrastructure. In Proceedings of the $34^{\text {th }}$ Int. Convention MIPRO. Opatija (Croatia), 2011, p. 407-412. ISBN: 978-953-233-059-5

[3] ZAFARUDDIN, S. M., BERGEL, I., LESHEM, A. Signal processing for Gigabit-rate wireline communications: An overview of the state of the art and research challenges. IEEE Signal 
Processing Magazine, 2017, vol. 34, no. 5, p. 141-164. DOI: 10.1109/MSP.2017.2712824

[4] KRINSKY, D. M., VEENEMAN, D. E., OLSHANSKY, R. Bandwidth selection for the very high-rate digital subscriber line (VDSL) system. In Proceedings of ICC/SUPERCOMM '96 International Conference on Communications. Dallas (USA), 1996, p. 1432-1436. DOI: 10.1109/ICC.1996.533645

[5] NORHAN, N., NURODDIN, A. C. M., ASROKIN, A. VDSL2 capacity performance evaluation: Simulation vs measurement. In Proceedings of IEEE Conference on Systems, Process and Control (ICSPC). Melaka (Malaysia), 2017, p. 140-145. DOI: 10.1109/SPC.2017.8313036

[6] MAZZENGA, F., GIULIANO, R. Log-normal approximation for VDSL performance evaluation. IEEE Transactions on Communications, 2016, vol. 64, no. 12, p. 5266-5277. DOI: 10.1109/TCOMM.2016.2613108

[7] TAKAHASHI, T., NIU, L., HUBING, T. Estimation of common mode current on coaxial cable with twisted wire pair. In Proceedings of International Symposium on EMC. Tokyo (Japan), 2014, p. 553-556. ISBN: 978-4-8855-2287-1

[8] HUAGANG WANG, MENG, T. R., WEN, L. S. Measurement and analysis of electromagnetic emissions for broadband power line (BPL) communication. In Proceedings of IEEE 5th International Symposium on Electromagnetic Compatibility. Beijing (China), 2017, p. 1-4. DOI: 10.1109/EMC-B.2017.8260355

[9] KASPER, J., MAGDOWSKI, M., VICK, R. Measurement of the stochastic electromagnetic field coupling to transmission line networks of single-line above a ground plane. In 2016 International Symposium on Electromagnetic Compatibility - EMC EUROPE. Wroclaw (Poland), 2016, p. 223-228. DOI: 10.1109/EMCEurope.2016.7739170

[10] DE ClerCQ, L., PEeTERS, M., SCHELSTRAeTE, S., et al. Mitigation of radio interference in $\mathrm{xDSL}$ transmission. IEEE Communications Magazine, 2020, vol. 38, no. 3, p. 168-173. DOI: $10.1109 / 35.825655$

[11] STOLLE, R. Electromagnetic coupling of twisted pair cables. IEEE Journal on Selected Areas in Communications, 2002, vol. 20 , no. 5 , p. $883-892$. DOI: $10.1109 /$ JSAC.2002.1007371

[12] OLSEN, R. G. Technical considerations for broadband powerline (BPL) communication. In. Proceedings of the $16^{\text {th }}$ International Zurich Symposium and Tech. Exhibition on EMC. Zurich (Switzerland), 2005, p. 1-6.

[13] COOK, J. W., KIRKBY, R. H., BOOTH, G. M., et al. The noise and crosstalk environment for ADSL and VDSL systems. IEEE Communications Magazine, 1999, vol. 37, no. 5, p. 73-78. DOI: $10.1109 / 35.762859$

[14] OKSMAN, V., STROBEL, R., WANG, X., et al. The ITU-T's new G.fast standard brings DSL into the gigabit era. IEEE Communications Magazine, 2016, vol. 54, no. 3, p. 118-126. DOI: 10.1109/MCOM.2016.7432157

[15] GALLI, S., KERPEZ, J. J., MARIOTTE, H., et al. PLC-to-DSL interference: Statistical model and impact on VDSL2, vectoring, and G.fast. IEEE Journal on Selected Areas in Communications, 2016, vol. 34, no. 7, p. 1992-2005. DOI: 10.1109/JSAC.2016.2566118

[16] SJOBERG, F., NILSSON, R., BORJESSON, P. O., et al. Digital RFI suppression in DMT-based VDSL systems. IEEE Transactions on Circuits and Systems, 2004, vol. 51, no. 11, p. 2300-2312. DOI: 10.1109/TCSI.2004.836865

[17] TEIXEIRA, E. A., DOS SANTOS, M. V. PLC-to-LAN interference analysis and electromagnetic shielding. In Proceedings of 2016 IEEE International Conference on Emerging Technologies and Innovative Business Practices for the
Transformation of Societies (EmergiTech). Balaclava (Mauritius), 2016, p. 194-198. DOI: 10.1109/EmergiTech.2016.7737337

[18] OKSMAN, V., STROBEL, R., STARR, T., et al. MGFAST: A new generation of copper broadband access. IEEE Communications Magazine, 2019, vol. 57, no. 8, p. 14-21. DOI: 10.1109/MCOM.2019.1800844

[19] ZHANG, C., HU, X., LIU, Y., et al. Multiple interacting narrowband interferences suppression algorithm for OFDM systems. IEEE Access, 2020, vol. 8, p. 62310-62321. DOI: 10.1109/ACCESS.2020.2984816

[20] DROOGHAAG, B., MAES, J., EL FANI, M., et al. Exploring field noise on G.fast frequencies. In IEEE Global Communications Conference (GLOBECOM 2017). Singapore (Singapore), 2017, p. 1-6. DOI: 10.1109/GLOCOM.2017.8254973

[21] WOLKERSTORFER, M., MECKLENBRAUKER, C. F. Variational inequality approach to spectrum balancing in vectoring xDSL networks. In Proceedings of IEEE International Conference on Communications (ICC). Paris (France), 2017, p. 1-7. DOI: 10.1109/ICC.2017.7997154

[22] MIKAC, V., ILIC, Z., BERISA, T., et al. Capacity analysis of RTbased VDSL2 copper access networks. In Proceedings of the $22^{\text {nd }}$ International Conference on Software, Telecommunications and Computer Networks (SoftCOM). Split (Croatia), 2014, p. 165-169. DOI: $10.1109 /$ SOFTCOM.2014.7039081

[23] ATTANASIO, V., PENNA, S., MARIER, G., et al. Ultra broadband access network performance in a multi operator scenario. In Proceedings of the 17th International Telecommunications Network Strategy and Planning Symposium (Networks). Montreal (Canada), 2016, p. 115-120. DOI: 10.1109/NETWKS.2016.7751162

[24] MAZZENGA, F., GIULIANO, R. Analytical performance evaluation of VDSL2. IEEE Communications Letters, 2016, vol. 21 , no. 1, p. 44-47. DOI: 10.1109/LCOMM.2016.2618369

[25] AL-NEAMI, I., HEALY, C. T., JOHNSTON, M., et al. Investigation into impulsive noise techniques for a G.fast system. In Proceedings of the 11th International Symposium on Communication Systems, Networks \& Digital Signal Processing (CSNDSP). Budapest (Hungary), 2018, p. 1-5. DOI: 10.1109/CSNDSP.2018.8471864

[26] AMEMIYA, F., KUWABARA, N., IDEGUCHI, T. Estimation of electromagnetic interference field emitted from telecommunications line. IEICE Transactions on Communications, 1995, vol. E78-B, no. 2, p. 159-167. ISSN: 0916-8516

[27] TAYLO, C. D., CASTILLO, J. P. On the response of a terminated twisted-wire cable excited by a plane-wave electromagnetic field. IEEE Transactions on Electromagnetic Compatibility, 1980, vol. EMC-22, no. 1, p. 16-19. DOI: 10.1109/TEMC.1980.303816

[28] MOULIN, F., OUZZIF, M., ZEDDAM, A., et al. Discretemultitone-based ADSL and VDSL systems performance analysis in an impulse noise environment. IEE Proceedings - Science, Measurement and Technology, 2003, vol. 150, no. 6, p. 273-278. DOI: 10.1049/ip-smt:20031072

[29] ITU-T. Telecommunication Union ITU-T Recommendation. Measuring Arrangements to Assess the Degree of Unbalance about Earth, ITU-T Rec. O.9. 1999, p. 1-21.

[30] CHAMBERLIN, K., KOMISAREK, K., SIVAPRASAD, K. A method of-moments solution to the twisted-pair transmission line. IEEE Transactions on Electromagnetic Compatibility, 1995, vol. 37 , no. 1 , p. 121-126. DOI: $10.1109 / 15.350252$

[31] ITU-T. Telecommunication Union ITU-T Recommendation. Emission Levels and Test Methods for Wireline Telecommunication Networks to Minimize Electromagnetic Disturbance of Radio Services, ITU-T K.60. 2016, p. 1-18. 
[32] ECC. Electronic Communication Committee. Criteria for the Assessment of Radio Interferences Caused by Radiated Disturbances from Wire-line Telecommunication Networks, ECC/REC/(05)04. 2005, p. 1-3.

[33] ECC. Electronic Communication Committee. PLT, DSL, Cable Communications (including cable TV), lans and their Effect on Radio Services, ECC Report 24. 2003, p. 1-112.

[34] RADIOCOMMUNICATIONS AGENCY. Electromagnetic Radiation from Telecommunications Systems Operating over Material Substances in the Frequency Range $9 \mathrm{kHz}$ to $300 \mathrm{MHz}$, MPT1570. 2003, p. 1-9.

[35] ITU-T. Telecommunication Union ITU-T Recommendation. Very High Speed Digital Subscriber Line Transceivers 2 (VDSL2), Rec. G.993.2. 2016, p. 1-252.

[36] WANG, J., SONG, X., SU, D. Near-field radiation calculation of irregular wiring twisted-wire pairs based on mode decomposition. IEEE Transactions on Electromagnetic Compatibility, 2017, vol. 59, no. 2, p. 600-608. DOI: 10.1109/TEMC.2016.2635263

\section{About the Authors...}

Josip MILANOVIC was born in Osijek, Croatia in 1978. He received the B.S., M.S. and Ph.D. in Electrical Engineering from the University of Osijek, Faculty of Electrical Engineering, in 2003, 2008 and 2016, respectively. He is working in the Croatian Regulatory Authority for Network Industries (HAKOM), currently as a Senior RF Spectrum Monitoring Expert. Additionally he is employed as Assistant professor in the Dept. of Communications at the Faculty of Electrical Engineering in Osijek. He is currently active in number of areas of research including computa- tional electromagnetics, electromagnetic compatibility (EMC) aspects of telecommunication systems, EMC measurement techniques, electromagnetic propagation modeling in complex media, and radiated immunity and emissions.

Ana KATALINIC MUCALO was born in Sarajevo, Bosnia and Herzegovina in 1980. She graduated electrical engineering at the University of Zagreb in 2005. She received her Ph.D. from the same university in 2013. Since graduation she has been working at the Croatian Regulatory Authority for Network Industries (HAKOM) as an expert and Senior Expert for Microwave and Satellite Networks, dealing mostly with frequency planning and crossborder coordination of fixed point-to-point and satellite links. She is currently Deputy Executive Director responsible for RF spectrum management. Her research interest is related to radio channel modelling for MIMO wireless systems, focusing especially on dynamic multipath effects, visibility regions parameterization and implementation of mobility. She is IEEE member. She has served several positions in Region 8 and Croatia Section. She currently serves as Croatia Section Vice-chair and is Croatia Section chair elect for 2021-2022.

Mario GAL was born in Nasice, Croatia in 1979. He received the B.S. degree in Electrical Engineering from the Faculty of Electrical Engineering in Osijek, Croatia in 2003. Since graduation he is working in the Spectrum Monitoring Department, Croatian Regulatory Authority for Network Industries (HAKOM), currently as a Senior RF Spectrum Monitoring Expert, dealing mostly with frequency and interference measurement in radiofrequency spectrum. 